\title{
The impact of traditional filial piety between older people and their children in Taiwan
}

\author{
Hui-Chi Li, Yu-Hua Lin *, I Lee
}

Department of Nursing, I-Shou University, Taiwan

\begin{abstract}
Article Details
Article Type: Commentary Article

Received date: $17^{\text {th }}$ August, 2016

Accepted date: $29^{\text {th }}$ Oct, 2016

Published date: $02^{\text {nd }}$ Nov, 2016

"Corresponding Author: Yu-Hua Lin, Department of Nursing, I-Shou University, Taiwan; 8 Yida Rd., YanchaoDistrict, Kaohsiung, Taiwan 82445; 886-7-6151100; E-mail: lin2368@isu.edu.tw

Citation: Li HC, Lin YH, Lee I (2016) The impact of traditional filial piety between older people and their children in Taiwan. J Comp Nurs Res Care 1: 103. doi: http://dx.doi.org/jenrc/2016/103.

Copyright: (C2016, This is an open-access article distributed under the terms of the Creative Commons Attribution License 4.0, which permits unrestricted use, distribution, and reproduction in any medium, provided the original author and source are credited.
\end{abstract}

\section{Abstract}

Filial piety is a significant traditional belief among Chinese people. However, social structural changes have created a limited number of people available to take care of the elderly. Elderly infirm parents may be sent to nursing homes when no family member is available to take care of them, which may effectively reduce older people's satisfaction in their later life. It also increases the caring stress from children because of this traditional belief.

\section{Keywords: Filial piety, Children responsibly, Nursing home}

The aging population has been increasing globally. In the USA, the percentage of people 65 years of age and over presently is $14 \%$, and predicted to rise to $19.7 \%$ in 2030 [1]. In Taiwan, $12.1 \%$ of the population is over 65 years of age, and will reach $41 \%$ in 2061 [2]. Family support plays a major role in providing elderly people care in many Asian societies [3]. Traditional cultural norms like filial piety illustrate the responsibility of children to take care of their parents; however, change of social structure has impacted the role of family support for the elderly.

Filial piety is the traditional belief among Chinese people, and is defined as respect, responsibility, affection and repayment [4]. Ancient proverbs indicate this: "Among all the good deeds, filial piety comes first," and describe the important responsibility of taking care of aged parents. The value of Confucian filial piety, the Chinese expression of "Xiao Tao" illustrates a complex obligation of children to take care their parents. This obligation include living with parents (or staying close if co-residence is not possible), cooking meals, serving, caring, and housekeeping [5]. Traditional Chinese filial piety also implies deep loyalty, respect, responsibility, and devotion by children to parents [3]. Sung [6] reviewed the Confucian literature about traditional meanings of respect for parents and identified 13 classical forms of caring. These forms were care, victuals, gifts, linguistic utterances, presentations, public displays, spatial allocation, celebrations, acquiescence, salutations, precedence, ancestor worship, and funeral respect. However, these traditional Confucian filial norms have been modified or even corroded through changes in social structure [3]. These social structure changes include the decreasing number of children, the nuclear family rather than the extended family, more women in the work force, and geographical separation distance [7], which limit the availability of people to take care of their elderly.

These limitations for family caregivers have also increased life dissatisfaction in older people. $\mathrm{Ng}$ and Phillips [3] found that in a case study in Hong Kong, the elderly living with adult children appeared to receive better emotional support than those living without children, and received more daily support from their adult children. Another study found parents with more emigrating children tended to have more depression and lower life satisfaction [8].

Older parents, especially the sick or frail, may be sent to nursing homes where there is a less limited availability of people to take care of them [9] However, more than 50\% of the elderly would not be willing to live in nursing homes [10], and prefer living with or being looked after by their family [11]. Possible reasons indicate that the elderly would feel deserted by their family, especially by their children, which also transgress the traditional belief of filial piety, and that older people want to live in their own home and die in their own home. A nursing home is not his/her own home.

Few studies have mentioned children's perception about sending their parents to nursing home. Children generally face pressure from society about their roles and responsibilities in taking care of parents, not to mention self-imposed feelings of guilt, particularly if they send their parents to a nursing homes [11]. Filial piety is also one of the factors for unwillingness to place patients in a nursing home [12]. The author has visited several nursing institutions and been informed by administrators there that most children or other family members felt guilty about sending their parents to a nursing home. They generally did not let their neighbors or other relations know that their parents had been sent to a nursing home by their own children. This kind of guilty feeling sometimes causes care difficulty, especially when communicating with (other) family members.

Filial piety deeply effects tradition beliefs in Taiwanese people. This difference between older people and their children in filial piety belief may reduce satisfaction of the elderly in their later life, and also increases caring stress for children. The nursing home is one of the 24-hour long-term care facilities in Taiwan, which conflicts with traditional filial piety belief between family caregiver and elderly parents. How to improve older people's quality of life in their later life and assist family support functioning should be considered in future long-term care policies.

\section{References}

1. U.S. Department of Health \& Human Services (2015) State Projections of Population Aged 65 and over: July 1, 2005 to 2030. 
2. Department of Household Registration (2016) Household registration statistics data analysis.

3. Ng ACY, Phillips DR, Lee WK-M (2002) Persistence and challenges to filial piety and informal support of older persons in a modern Chinese society: A case study in Tuen Mun, Hong Kong. J Aging Stud 16: 135-153.

4. Sung K-T (1998) An exploration of actions of filial piety. J Aging Stud 12: 369-386.

5. Cheng ST, Chan AC (2006) Filial piety and psychological wellbeing in well older Chinese. J Gerontol B Psychol Sci Soc Sci 61: 262-269.

6. Sung K-T (2001) Elder respect: exploration of ideals and forms in East Asia. Journal of Aging Studies 15: 13-26.

7. Chao SY, Roth P(2005) Dimensions of quality in long-term care facilities in Taiwan. J Adv Nurs 52: 609-618.

8. Guo M, Aranda MP, Silverstein M (2009) The impact of outmigration on the inter-generational support and psychological wellbeing of older adults in rural China. Age Soc 29: 1085-1104.

9. Han HR, Choi YJ, Kim MT, Lee JE, Kim KB (2008) Experiences and challenges of informal caregiving for Korean immigrants. $J$ Adv Nurs 63: 517-26.

10. Ministry of Health and Welfare (2013) Report of the Senior Citizen Condition Survey.

11. Wang S-Y (2011) Nursing home placement of older parents: An exploration of adult children's role and responsibilities. Contemporary Nurse: A J Aus Nurs Profes 37: 197-203.

12. Chiu L, Shyu W-C, Liu Y-H, Wang S-P, Chang T-P (2001) Factors determining the attitudes of family caregivers of dementia patients toward nursing home placement in Taiwan: comparisons between urban and semiurban areas. Public Health Nurs 18: 281-291. 